\title{
Minu San Martín Aróstegui. La pintura interior
}

\author{
Minu San Martín Aróstegui. The inner painting \\ SONIA D'Agosto ForTEZA \\ Becaria FPU del Departamento de Historia del Arte de la Facultad de Geografía e Historia \\ Universidad de Sevilla \\ sdagosto@us.es
}

Recibido: $26 / 01 / 2015$

Aceptado: 25/04/2015

\begin{abstract}
Resumen
En este trabajo se da a conocer la trayectoria vital y profesional de la pintora Minu San Martín Aróstegui. Artista nacida en San Sebastián con un interesante recorrido en el que podremos rastrear la belleza plástica que emana de la fusión entre el Romanticismo occidental y la filosofía Taoísta.

\section{Palabras clave}

San Martín, Pintura, Posmodernismo, Romanticismo, Dinastía Song, Euskadi.

Abstract

In this work one occurs to know the vital and artistic trajectory Minu painter San Martin Aróstegui. Artist born in San Sebastián with an interesting artistic route where we will be able to track the plastic beauty which is born from the fusion between the western Romanticism and the Taoism philosophy.
\end{abstract}

\section{Keywords}

San Martin, Painting, Posmmodernism, Romanticism, Song Dynasty, Euskadi. 
Referencia normalizada: D'AGOSTO ForTEZA, S. (2015): “Minu San Martín Aróstegui. La pintura interior". Arte y Ciudad. Revista de Investigación, no 7 (abril), págs. 97-120. Madrid. Grupo de Investigación Arte, Arquitectura y Comunicación en la Ciudad Contemporánea, Universidad Complutense de Madrid.

Sumário: 1.- Introducción. 2.- Vocación. 3.- Formación Académica. 4.- Inicios profesionales. 5.- Materiales y técnicas. 6.- Estilo. 7.- Descubriendo el qué y el cómo. 8.- Dualidades. 9.- Tiempo de cambios. 10.- Pintor y observador se hacen uno. 11.- Bibliografia.

\section{1.- Introducción.}

Este artículo surge a raíz de la muestra Paisajes de mi memoria, celebrada en el verano de 2013 en la Sala de Exposiciones de la Biblioteca Municipal de Alhaurín El Grande (Málaga), donde tuve la oportunidad de conocer personalmente a la pintora Minu San Martín Aróstegui, artista de vocación y con una profunda filosofía que impregna toda su obra.

\section{Vocación.}

La pintora Minu San Martín Aróstegui nació en San Sebastián en 1964. De tempranas inquietudes artísticas, comenzó a pintar aproximadamente a los nueve años de edad. Esas inquietudes surgieron en el momento que Minu observó el cuadro pintado por su amigo Ricardo Zaldúa, un paisaje cuyo tema era el Monte San Antón, también conocido como el Ratón de Guetaria. Aquello la dejó fascinada. Desde aquel momento supo que quería pintar y la pintura pasaría a ser una afición verdaderamente placentera, que presagiaba la futura vocación de la pintora.

Minu San Martín nunca aceptó tomar clases porque para ella la pintura era su gran juego y no quería que se convirtiera en una obligación. Su madrina, Ana María Parra Gómez (San Sebastián, 1928) ${ }^{1}$, artista a la que San Martín tenía como referencia más próxima, apoyaba su postura de desarrollar de

\footnotetext{
${ }^{1}$ Pintora que llegó a destacar notablemente en el retrato y el paisaje, además de ser una aventajada discípula de Ascensio Martiarena (San Sebastián, 1884 - 1966).
} 
forma independiente su creatividad, opinión que era compartida por Rafael Ruiz Balerdi (San Sebastián, 1934 - Altea, 1992)², amigo de la familia.

En esos primeros años, San Martín se intenta formar de manera autodidacta, impregnándose de imágenes de cuadros famosos. En busca de ellas, devora cuantos libros caen en sus manos, recorta las láminas de los calendarios y colecciona postales. Después copiaba aquellas reproducciones, en particular las de los paisajes de los pintores impresionistas. Cuando el tiempo se lo permitía, salía a pintar del natural los parajes de su Guipúzcoa natal, sobre todo los alrededores de Zarautz, localidad donde veraneaba con su familia todos los años. Era una escena habitual verla en su bicicleta, con un caballete plegable, la caja de pinturas y un lienzo, partiendo a la búsqueda de un estudio al aire libre en el que pintar. Entre sus motivos favoritos estaban los caseríos y el mar. Éste último será un tema muy recurrente en su producción (Fig.1). En algunas ocasiones la joven pintora se quedaba en casa y ejecutaba sus lienzos desde la memoria, añadiendo motivos que no existían y que generaba su imaginación. En otras, se dejaba impresionar por las propias vivencias plasmándolas en la tela. Así sucedió cuando la joven pintora, a la edad de 15 años, presenció el atentado, acaecido el 27 de noviembre de 1980, donde fue asesinado el jefe de la Policía Municipal de San Sebastián, el teniente coronel del Ejército retirado, Miguel Garciarena (Fig. 2). En el lienzo, se plasmaba claramente el desgraciado suceso que describían los periódicos (Ruíz de Azúa, 1980)

Cuando cumplió 16 años, supo que iba a dedicarse a la pintura y pensó en cursar la carrera de Bellas Artes. Para su formación no concebía otra vía distinta a la de cursar estudios universitarios, pues sus progenitores también los tenían. Fue tan clara aquella determinación, que hasta tenía elegida la universidad donde hacerlos, y un año antes de pedir el traslado de matrícula se empadronó en la ciudad de Barcelona. Fue en ese momento, cuando San Martín decidió tomar sus primeras clases de pintura en el taller del pintor Julián Ugarte Munozábal con la intención de presentarse al año siguiente

${ }^{2}$ Fue una de las figuras emblemáticas de la vanguardia plástica vasca de las últimas décadas del siglo XX y uno de los fundadores, en 1966, del mítico Grupo Gaúr, colectivo del que formaban parte artistas como Oteiza, Chillida, Basterretxea, Amable Arias, Remigio Mendiburu, Zumeta y Sistiaga.

${ }^{3}$ Para ampliar información consúltese en: http://elpais.com/diario/1980/11/28/espana/344214001 _850215.html, El País, San Sebastián, 28 de noviembre de 1980, recuperado el 15/12/2013. 
al examen de ingreso en la Facultad de Bellas Artes de la Universidad de Barcelona4. Con Ugarte recibió clases intensivas de dibujo clásico y pintura tradicional, aprendiendo a dominar el escorzo, la perspectiva y el dibujo del natural. Pintaban casi todos los días de la semana, trabajando a fondo el dibujo a carboncillo para pasar posteriormente al manejo del color con la técnica del óleo. Salían al campo a pintar los pueblos, y en especial sus calles en pendiente con el fin de aprender a dominar la perspectiva cónica a mano alzada. Trabajaban el dibujo sobre lo que se les pusiera por delante: los edificios de San Sebastián, los puentes del río Urumea, los barcos del puerto, los caseríos de los alrededores de la ciudad, etc. Todo un repertorio de ejercicios que darían a la pintora unas bases para enfrentarse con el examen de acceso, que realizaría en el mes de octubre de 1983, aprobándolo sin dificultades (Fig. 3).
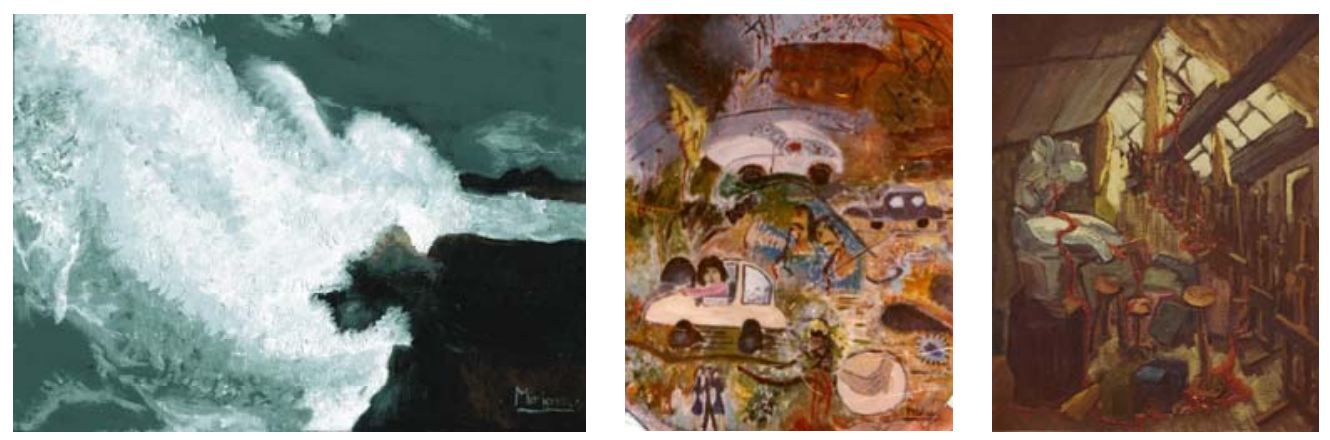

Figs. 1 - 3. Minu San Martín. El mar (o/1 35x26,5 cm. 1977); Atentado de Miguel Garciarena (o/1 $35 \times 26,5 \mathrm{~cm} .1980)$; Examen de ingreso (o/t, 1983).

Cabe preguntarse por qué la futura artista decidió estudiar en la Ciudad Condal y no en Bilbao, donde había una Facultad de Bellas Artes. La respuesta era muy sencilla: por su tradición artística. Allí vivieron y trabajaron artistas míticos como Dalí, Picasso, Miró o Gaudí y se desarrollaron foros artísticos tan fecundos como Els Quatre Gats, cervecería en la que jóvenes artistas de la bohemia barcelonesa se reunían, discutían, exponían y donde incluso se editó una revista que sirvió de órgano a sus inquietudes plásticas. En consecuencia, ella quería conocer la ciudad que dio cobijo a tanta vanguardia, buscando poder sumergirse en lo que quedara de aquel movimiento cultural.

${ }^{4}$ Pintor nacido en Zarautz en 1929, de tendencia expresionista constructiva. 


\section{Formación Académica.}

En el transcurso de la carrera recibió la docencia, entre otros, de profesores como Jaume Coll, Raimon Arola, Luis Guembè, Estela Ocampo, Alberto Cardín, Victoria Combalía, Joaquín Chancho y Hernández Pijuán. Todos ellos influyeron en esta etapa formativa, unos más que otros, como la misma artista reconoce en la dedicatoria de su tesis doctoral. De aquellos años la pintora recuerda muy positivamente el giro que dio su pintura, gracias al trabajo desarrollado con el grupo de Jaume Coll. Desde la adolescencia arrastraba una forma de pintar de aires surrealistas, como se advierte en obras tan representativas de los inicios de su carrera como el Atentado de Miguel Garciarena o el lienzo -Sin título-, que realizó para el examen de ingreso a la Facultad (Figs. 2 y 3); pero junto a Coll aprendió a entender la pintura no como la representación del aspecto externo de la realidad, sino de su esencia, de su razón de ser. Assumpció Mateu ${ }^{5}$, como responsable de pintura de este grupo, marcaría poderosamente su posterior trayectoria profesional, tanto en sus planteamientos estéticos como en la carga interpretativa de los mismos.

San Martín se licenció en el año 1988, con un excelente expediente académico, aunque continuó su formación cursando los estudios de doctorado que impartía la Facultad de Bellas Artes barcelonesa dentro del programa "Estructura de la Imagen y del Entorno". Los culminó en 1997 con la lectura de su tesis doctoral, El instante y la eternidad. Un tiempo de la pintura, que obtuvo la calificación de apto cum laude (San Martín Aróstegui, 1997).

\section{Inicios profesionales.}

Una vez licenciada, inició una frenética carrera de actividades, simultaneando la elaboración de su tesis doctoral con el ejercicio de la docencia en diferentes centros de Formación Profesional de Barcelona, desde 1989 hasta 2004, desarrollando su creación artística y redactando textos para libros de pintura y escultura (San Martín Aróstegui, 1991), y artículos para diferentes revistas de arte (San Martín Aróstegui, 1989a, 1989b; 1990a, 1990b; 1992; 1995a; San Martín Aróstegui y Carné, 1989 y 1992). Todas estas inquietudes intelectuales culminarán con la fundación en 1995 de la Asociación de Arte

\footnotetext{
${ }^{5}$ Assumpció Mateu Negre (Gerona, 1952), pintora de tendencias informalistas que trabaja temáticas relacionadas con la naturaleza y el paisaje.
} 
Contemporáneo Triangle, donde trabajará junto a la crítica de arte Montserrat Carné y la artista Assumpció Mateu, que pronto se desligará del proyecto. En ella desarrollaría multitud de actividades, desde la celebración de exposiciones, la preparación de publicaciones y el montaje de instalaciones y performances, hasta la organización de cursos, conferencias y coloquios. Dicha asociación, que prolongó su actividad hasta 1999, llegó a tener un impacto tan positivo en la ciudad que fue reconocida como una de las 20 galerías de arte más prestigiosas de Barcelona (De La Villa, 1998: 259), siendo sus eventos recogidos por El País de las Tentaciones, publicación semanal, suplemento del diario El País, considerada en aquellos años como el escaparate de la modernidad (J.B., 1995: 48; Vidal, 1996: 10; V.J., 1997).

La trayectoria artística de San Martín, propiamente dicha, se inició en el taller que instaló en la planta baja de una antigua casona de la calle Montserrat de Esplugues de Llobregat, junto con el también pintor José $\mathrm{M}^{\mathrm{a}}$ Luffiego y la escultora Uka Nin. Allí pintó todas las obras de su primera exposición individual, celebrada en 1991 en la Galería Estudio de San Sebastián (J.D.E., 1991). En esta muestra quedaba perfectamente reflejado el trabajo de sus primeros años de andadura independiente ${ }^{6}$. Sus elementos de inspiración fueron los árboles y los pájaros que contemplaba desde la ventana de su estudio (Fig. 4); las tierras desgarradas por el agua o barridas por el frío y el viento; el mar, siempre latente en su retina; la figura humana, como solitaria protagonista de su propio espacio o el abismo abierto del cielo, preferentemente en las horas del crepúsculo y del amanecer. En estos primeros trabajos podía advertirse cómo la pintora jugaba con todas las técnicas aprendidas en sus años de estudio y cómo iba definiendo los materiales y la utilización que de los mismos llevaría a cabo de ahí en adelante.

\section{Materiales y Técnicas.}

A lo largo de su formación en la carrera de Bellas Artes, San Martín tanteaba todas las técnicas a su disposición, y aun manteniéndose fiel al carboncillo a la hora de dibujar, al pintar se sentía muy atraída por la técnica de la encáustica. En su ejecución se asemejaba a una especie de óleo de secado rápido, pe-

\footnotetext{
${ }^{6}$ Hay que tener en cuenta que las fechas de terminación de las obras y exhibición de las mismas, podían ser muy distintas. Por ejemplo, en el año 1990, inicia en Menorca una serie sobre el paisaje mediterráneo que no exhibirá en la Sala de Cultura de "Sa Nostra", hasta llegar al año 1993.
} 
ro su práctica exigía tal velocidad y destreza, que resultó excesiva para la pintora y aunque le parecía muy atractiva, no continuó por ese camino. Más adelante encontró una forma de efectuar trabajos con un secado rápido: el acrílico que, a pesar de no tener la intensidad matérica y el brillo de la cera, era más práctico, ya que no necesitaba tanta preparación como la que precisaba la técnica de la encáustica. Durante aquellos años también practicó el collage, que desde entonces se integra de una forma muy natural en los cuadros al óleo.

Fig. 4. Minu San Martín. Árbol I. Mixta sobre tela 130 x $81 \mathrm{~cm} .1989$.

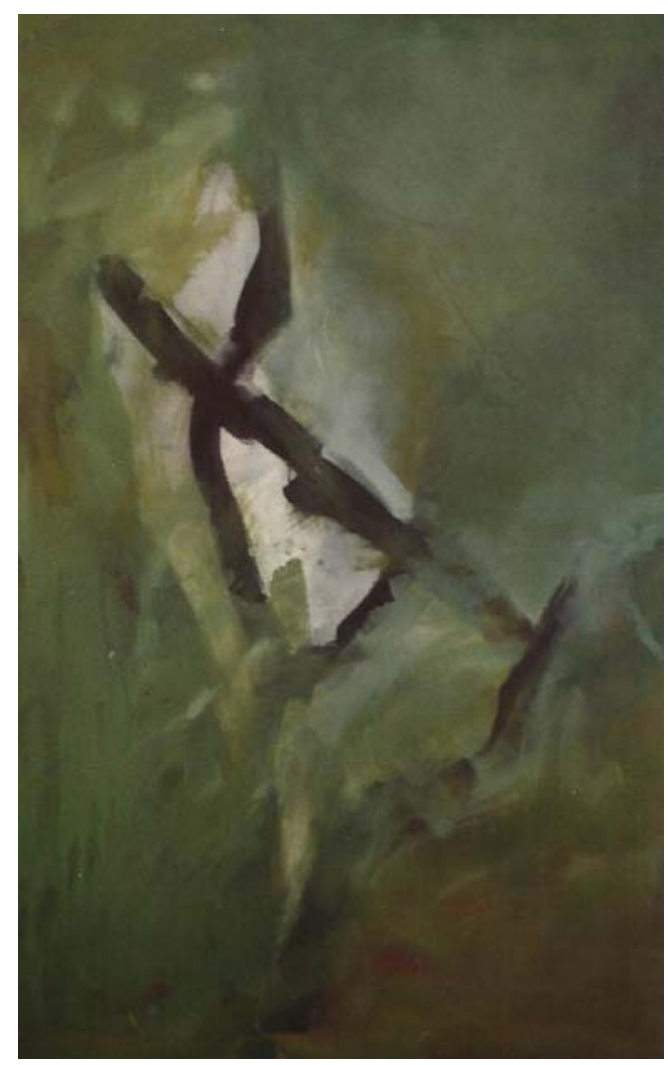

Actualmente la pintora concibe el material, la técnica y el motivo como herramientas propias de la pintura, que están ahí para ser utilizadas con total libertad, en función de las particulares necesidades creativas de cada momento ${ }^{7}$. Así, aunque el óleo sobre tela es su medio por excelencia, cuando toma notas del natural, siempre lo hace con acuarela, para lo que lleva consigo una

${ }^{7}$ D'Agosto, S., (2013) Entrevista con la pintora I, 19 de agosto. 
caja pequeña de pastillas que le permite pintar en cualquier lugar. Otro material que le causa verdadera pasión es la tinta china. Suele combinarla con el acrílico y en algunas ocasiones con tintas de color, aunque no es lo habitual. En algunas obras de pequeño formato usa óleo sobre papel, técnica que complace mucho a la artista, pues el pincel no se desliza de una forma ligera y ágil. Esta circunstancia obliga a la pintora a mover el pincel con fuerza, imprimiendo su propia voluntad sobre la superficie. El color se agarra al papel pero no de una forma plana, sino lleno de matices y transparencias, con una sensación muy orgánica, muy viva, dando un efecto como si se rastrillara la tierra.

Lo que más motiva a la pintora en las técnicas del óleo y del carboncillo es su fuerza. Le atrae la firmeza del trazo que le permite la calidad del carboncillo y su rotundidad cuando no se difumina. Lo mismo pasa cuando trabaja el óleo, cuya pasta aplica dejando todo su vigor, brillo y luminosidad, casi dando la posibilidad de ser moldeado. Le gusta el intenso olor que desprende el aceite de linaza, la esencia de trementina y el ritual de preparación de los soportes, donde emplea una mezcla rugosa de blanco de España y cola, que extiende sobre el lienzo de loneta cruda. En esas superficies, la pintora trabaja con brochas duras y espátulas, con lo que cada pincelada y cada recorrido de espátula tienen un peculiar sonido del que siempre está pendiente. De hecho la pintora recuerda que cuando impartía clases solía escuchar el sonido del trazo del lápiz o del carboncillo sobre el papel para saber si el alumno estaba trabajando bien el material. Y junto al óleo, quizás la tinta china sea la técnica y el material más sugerente para la pintora, ya que su color negro le inspira profundidad. Para ella la densidad del negro de la tinta equivale a lo matérico en el óleo. La naturaleza de la tinta china permite a la pintora hacer fluir el gesto con fidelidad, concepto importantísimo en su producción y elemento clave de su estilo.

\section{Estilo.}

Minu San Martín entiende que el estilo es precisamente lo que subyace tras el material, la técnica y el motivo. Intenta unificar estos elementos en su interior otorgándoles la mayor coherencia y sinceridad posibles. Así, en la medida que el autor adquiere una madurez personal, así también la adquirirá su obra. Por este motivo, cuando interrogamos a la artista por su estilo, se siente incapaz de definirlo, porque considera estar inmersa en un continuo aprendizaje, repleto de pequeños descubrimientos, pero lejos aún de una respuesta definitiva. 
A pesar de lo que nos cuenta la pintora, nuestra labor como historiadores del arte nos obliga a definir su estilo, aunque sea a grandes rasgos. Y son precisamente sus propias palabras las que nos llevan a encuadrarla entre los postulados del posmodernismo, no solo por su libertad en el uso del material y de la técnica, sino también por su insistencia en la actitud independiente del artista, buscando huir de todo planteamiento racional que pueda entorpecer la fluidez de los recursos intuitivos. Tampoco podemos dejar de percibir la fuerte influencia de la estética Taoísta en toda su obra, fruto de los estudios realizados en su tesis doctoral, que se sumergen en una comprensión profunda de las siguientes estéticas: el Romanticismo occidental y la pintura de paisaje oriental de la Dinastía Song. En este sentido, la aproximación a la caligrafía china y a la pintura oriental es una gran aportación a su pintura gestual, en la que el gran movimiento de la pincelada está guiado por la intuición, no existe ninguna interferencia intelectual y el gesto surge de su brazo con un movimiento de puro instinto, que nace del estómago, sin pasar por la cabeza.

El interés profundo y permanente del arte chino está en demostrarnos que los problemas fundamentales casi no varían en el tiempo y en el espacio. La obra de arte es, para el artista, una etapa de su vida interior, en curso de cristalización, su visión del mundo, la esencia primordial de su existencia, de su razón de ser. Es la respuesta plástica que él crea de su problema de vivir. (Sterling, 1959: 14).

En lo que se refiere a las influencias que pudieron ejercer otros artistas de fama reconocida en la configuración de su estilo, nos remitimos a una entrevista donde le preguntaron a la pintora cuáles eran sus pintores favoritos y qué había aprendido de ellos. Contestó que todo lo que había podido, y que le interesaba

el ambiente de Friedrich, el espacio de Turner, la pincelada suelta de Cy Twombly, el orden de Cézanne, la libertad de color de Matisse, el blanco de Fortuny, la combinación de materia de Munch, el movimiento de Bacon, la profundidad de Rothko, la tenacidad de Van Gogh, la espontaneidad de Klee, la agilidad y relación con la vida de Toulouse Lautrec, el dibujo de Ingres y de Picasso... Picasso (Juan, 2001: 27).

Como podemos observar, esta respuesta nos ofrece una información muy diversa que habla, una vez más, de un aprendizaje continuo, en el que San Martín abraza el lenguaje que mejor se adapta a cada momento. Este eclecticismo es otra característica que la define como una artista posmoderna, cir- 
cunstancia que se puede rastrear en toda su trayectoria artística, comenzando por su pintura inicial de tintes surrealistas para evolucionar hacia un neoexpresionismo muy cercano a pintores alemanes de la transvanguardia, como Anselm Kiefer, artista de pincelada matérica y gestual, con fuertes influencias del Romanticismo germano.

\section{Descubriendo el qué y el cómo.}

Continuando en la senda de sus primeros trabajos, después del inciso sobre las técnicas, los materiales y el estilo de su arte, tendríamos que hacer alusión a las dos exposiciones individuales que Minu San Martín realizó en Menorca, lugar al que comenzó a viajar a partir de 1989. También en ese año pronunció la conferencia titulada El arte moderno: Crisis o renovación (Benejam, 1989), impartida en la Sala El Roser del Ayuntamiento de Ciutadella de Menorca. El tema que desarrolló en ella le preocupó hasta tal punto, que lo incorporó a las investigaciones de su tesis doctoral de la que, años más tarde, constituiría un apartado clave.

Las exposiciones menorquinas, realizadas en las Salas de Cultura Sant Josep de Ciutadella y Sant Antoni de Maó durante el año 1993, marcaron un antes y un después en la trayectoria profesional de la pintora (Petrus, 1993; Melis Pons, 1993). Con motivo de estas dos últimas exposiciones, la entidad financiera Sa Nostra, publicó el libro Paisatge endins de la colección Poesia Estesa, donde se conjugaban en un proyecto común la prosa poética de la filóloga menorquina Josefina Salord Ripoll con las pinturas de Minu San Martín.

Ambas muestras giraron en torno a su particular visión de los paisajes de la isla de Menorca. En las obras prevalecía la línea horizontal, incidiendo en los contrastes lumínicos de la tierra y en el cambiante cromatismo de los fondos marinos de la isla (Fig.5). Y mientras pintaba aquellos lienzos, Minu San Martín descubrió que el motivo y el tema de la obra no eran una misma cosa, porque el motivo podía repetirse todas las veces que hiciera falta pero el tema no. El significado abstracto de cada obra, o dicho de otra forma: el tema, era el modo en que era llevado el motivo a la tela, otorgando a la obra multitud de matices y significados.

Es interesante observar, una vez más, la influencia que ejerció en su trabajo el estudio que por aquel entonces realizó para su tesis doctoral sobre los 
pintores románticos Caspar David Friedrich y Joseph Mallord William Turner. La pintora funde, en su propia obra, los lenguajes de ambos: del léxico de Friedrich aprovecha su carga simbólica y los aspectos más espirituales de su producción; de Turner, la expresión, la pasión, la indefinición, el vigor del color y la luz. Minu San Martín se apoya en la filosofía oriental como elemento armonizador de todas las cosas y entiende que los lenguajes de los pintores anteriores son complementarios y que al final, conforman una unidad. Son el qué y el cómo de una misma pregunta.
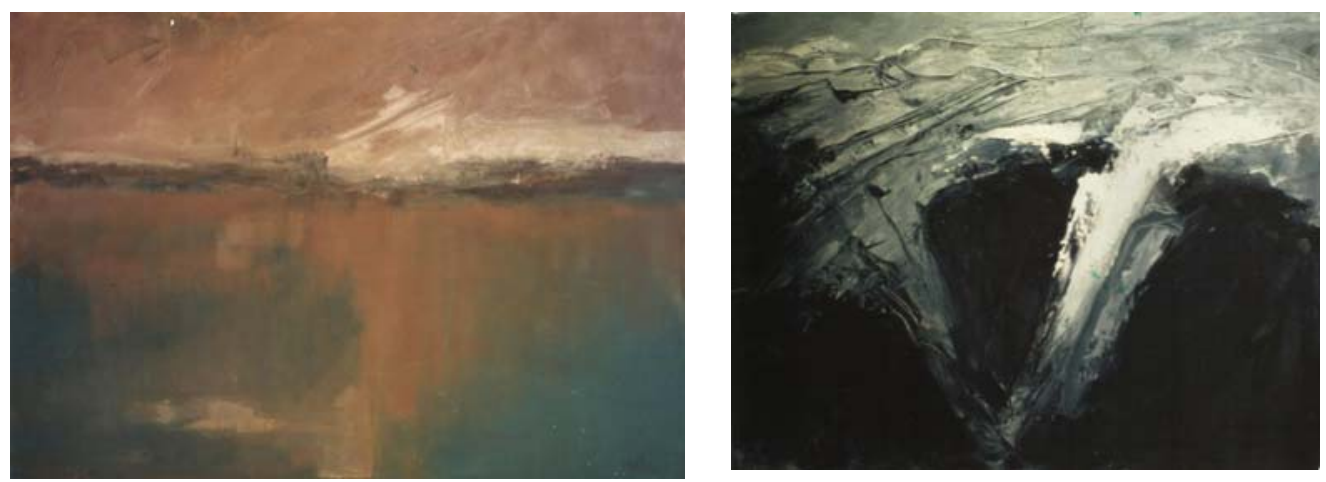

Figs. 5 - 6. Minu San Martín. Menorca continuidad (o/l, 114 x 162 cm., 1990) y Armonía áspera (o/t, $116 \times 89 \mathrm{~cm} ., 1992)$.

Al trabajo de Menorca le sucedieron varias series de obras motivadas por los diversos viajes que la pintora llevó a cabo. De esta manera, nos encontramos primero con varios lienzos que hablan de una estancia en Albarca, un pequeño pueblo del interior de Tarragona, y después con un viaje estival a Innsbruck (Austria), en 1991, en el que la pintora quedó impresionada por las altas montañas del Tirol, los fuertes contrastes entre el verde y la roca y, sobre todo, por la forma en que las cumbres se relacionaban entre sí formando lo que la artista entendía, como grandes coronas (Fig.6). Toda esta obra estaba regida por una verticalidad que no existía en su etapa de producción menorquina. Paulatinamente, la representación de las grandes montañas se iba simplificando hasta convertirse en abstractos triángulos blancos sobre fondo azul (Fig.7). Era la primera vez que San Martín llegaba a esa abstracción a partir de un ejercicio al que después llamaría "sistema de desarrollo de ideas". El ejercicio consistía en sentarse ante un cuaderno en blanco, elegido de antemano como soporte por tener unas hojas de superficie evocadora, con todo el material al alcance y, a 
partir de una sencilla imagen de inicio, dejarse llevar página a página, utilizando la razón lo menos posible y sin proyecto previo de ningún tipo. Desde ese momento este "sistema" sería utilizado por la artista como una forma habitual de trabajo.
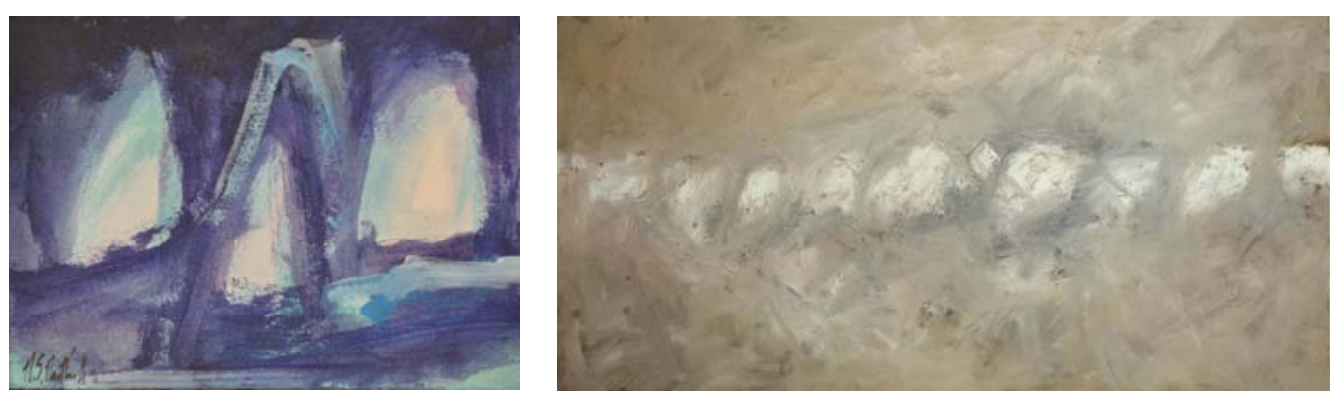

Figs. 7 - 8. Minu San Martín. Tirol (acrílico y tinta china sobre papel, 23 x $17 \mathrm{~cm}$., 1991) y Monegros, camino de paso (o/t, 195 x 97 cm., 1992).

\section{Dualidades.}

Minu San Martín a menudo iba a ver a su familia a San Sebastián, y en esos continuos desplazamientos de tren, se fue familiarizando con la imagen árida y gris del desierto de los Monegros, estampa que durante casi tres años sería recurrente en sus obras (Fig. 8). Este trabajo se enriqueció con varias visitas a los pueblos de Candasnos (Huesca), Bujaraloz (Zaragoza) y a sus alrededores, lugares en los que la pintora se dedicó a tomar notas del natural en las diferentes épocas del año y a escribir en su diario de taller:

Los Monegros están viviendo en mis telas; han pasado por las estaciones como si el sol, el calor, la lluvia, el viento hubieran hecho mella en ellos. Parece que los cuadros capten, como la tierra real, el ambiente que me rodea. Tengo la impresión de que la idea 'Monegros' está cobrando vida propia y se mueve y evoluciona como una tierra cultivada; temerosa del invierno y de la sequía del verano. Tienen sus propios sentimientos y yo los comparto. En este momento el color ha estallado y está en pleno auge de primavera ${ }^{8}$.

Si en la obra del Tirol había prevalecido la vertical como base de la composición, en la obra de los Monegros se vuelve a recuperar la horizontal, que ya había sido la tónica en la serie de Menorca. Esta alternancia de líneas se repite

\footnotetext{
8 San Martín Aróstegui, M., (1993), Diario de Taller, 8 de junio, Esplugues.
} 
en toda la trayectoria de San Martín y, del mismo modo que la vertical se combina con la horizontal, se combinan también otros elementos como: materia y transparencia (Fig. 9), espacio vacío y espacio lleno, telas muy grandes y papeles muy pequeños, contrastes extremos de color, etc. Este proceso nos sugiere la búsqueda por parte de la artista de un equilibrio en su producción, a través de la alternancia de opuestos. Pero hay que remarcar que estos "opuestos" occidentales no son más que las dos caras de una misma moneda en el pensamiento taoísta, el yin-yang, cuyo análisis ocupa buena parte de la tesis doctoral de la pintora. En este dejarse impregnar por los conceptos estudiados de forma teórica, se observa cómo en Minu San Martín la obra pictórica constituye un todo indisoluble con la persona, con su entorno y con todas sus actividades cotidianas.

En 1993, un traslado de residencia en la misma Barcelona la llevó a un ático situado en el no 3 de la calle Enrique Granados. Las vistas privilegiadas del nuevo domicilio abrieron a la pintora un renovado marco de referencias para inspirarse y reflexionar. Desde que llegara a la capital catalana había echado de menos el espacio. Valga decir que las primeras obras que pintó en esta ciudad (estudiando la licenciatura), representaban los túneles y los pasillos del metro.

Desde este nuevo mirador, la ciudad se le hacía a San Martín transparente y diáfana. El cielo que envolvía las numerosas cúpulas y tejados, cobraba quizás más importancia que éstos. Sobre las techumbres del barrio antiguo contrastaba el enorme vacío del cielo que las envolvía. Los ecos de aquella ciudad medieval, que todavía se resistía a desaparecer engullida por la gran urbe, inspiraron a la pintora una espiritualidad gótica que quedó reflejada en sus telas (Fig. 10). La exposición que realizó en 1994 en la Galería Olaetxea de San Sebastián, titulada Ciudad escondida, es un buen ejemplo de ello (San Martín Aróstegui, 1994).

Una vez más afloró la necesidad de equilibrar los contrarios y, a la ciudad como motivo, le siguió el mar Cantábrico. La Sala de Torre Luzea (magnífico ejemplo de gótico civil), en la villa de Zarautz, fue el destino elegido para exponer su nuevo trabajo, en 1995 (Fig. 11). Ese mismo año también exhibió en la Galería Hemen de Guetaria un considerable número de lienzos y papeles recopilados de la década 1985-1995 (San Martín Aróstegui, 1995b). 

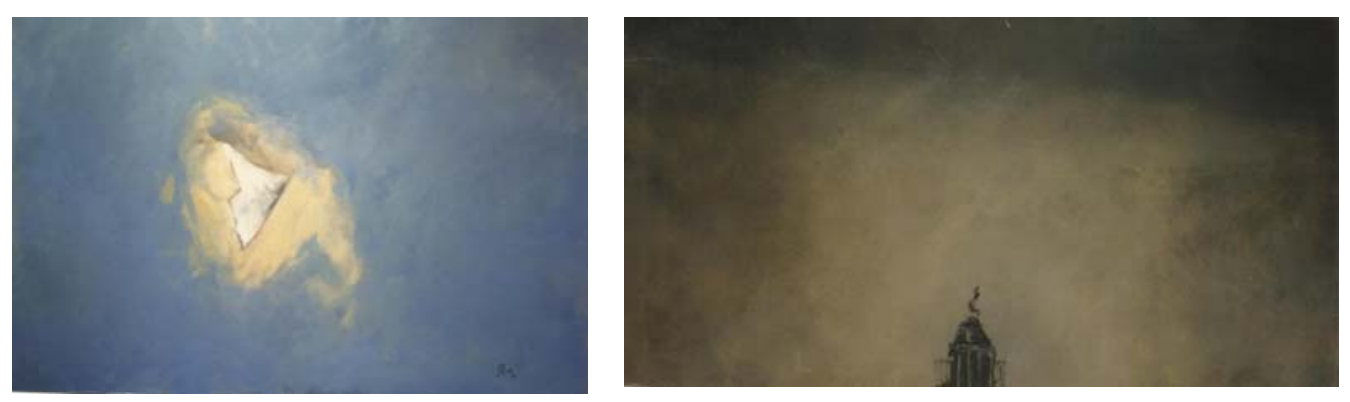

Figs. 9 - 11 Minu San Martín. (izq.): Quietud azul (o/t, 195 x $130 \mathrm{~cm}$., 1989); (drch.): En soledad (o/t, $90 \times 46$ cm., 1995); (inf.): Autorretrato (o/t, 91 x $73 \mathrm{~cm} ., 1999$ )

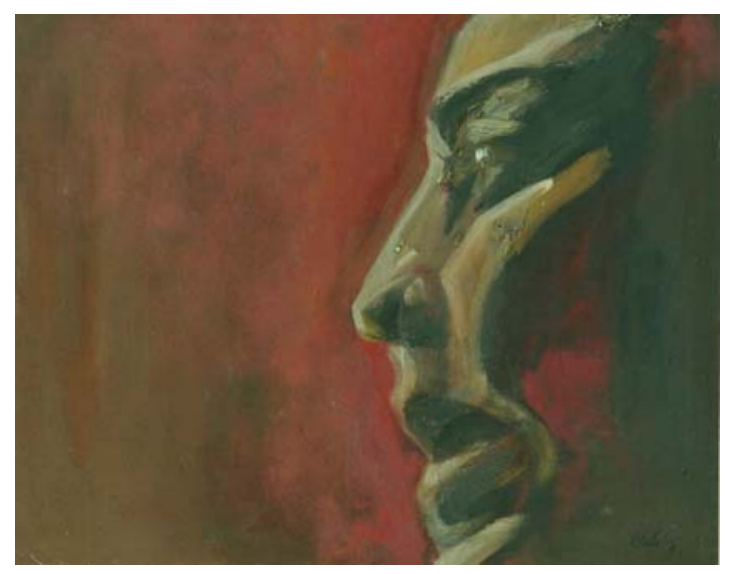

\section{Tiempo de cambios.}

En el mes de mayo de 1997 San Martín obtenía el título de Doctora en Bellas Artes y, poco tiempo después, entraba en crisis, como ella misma explica:

Después de tantos años persiguiendo sueños, los sueños se habían cumplido y, con ello, una especie de vacío se apoderaba del presente. Parecía que ya no quedaba nada por hacer9.

Ese sentimiento de impotencia se vio reforzado por muchos factores: una crisis sentimental; la sensación de que la eufórica Barcelona 92 ya estaba desfondada como foco cultural; un cambio en la ley de educación que le afectó reduciendo las clases que impartía a la mínima expresión; y el cierre definitivo de la Asociación Triangle. Arrancaba así una época de inestabilidad y excesos nocturnos, que la arrastraron a una espiral de desencanto. En la obra de estos años, es la primera vez que surge el retrato como reflejo directo

${ }^{9}$ D' Agosto, S., (2013) Entrevista con la pintora I, 19 de agosto. 
de ese oscuro estado de ánimo (Fig. 11). La pintura de esta etapa es de trazo enérgico, colores tenebrosos, casi infernales, que reflejan el estado de inquietud en que se hallaba la artista. En otras obras, se insinúa una luz tras una puerta, anunciando la esperanza de una resolución del conflicto (Fig. 12). En los paisajes de ese periodo, la luz es pobre y la sensación de angustia, confusión o desazón, vendrá dada por una paleta oscura y unas limitadoras geometrías horizontales o verticales en los extremos del lienzo, que asfixian y no permiten avanzar al objeto de representación en ninguna dirección. En la obra Siempre el Cantábrico (Fig. 13), las limitaciones geométricas alrededor del mar crispado, podrían ser la representación simbólica del intento de controlar las pasiones, tal y como lo vieron los románticos. La pintora aquí se convierte en espectadora pasiva de su propio drama, al que asiste impotente. Se queda de observadora y siente la fuerza de la angustia del que se sabe incapaz de resolver un problema.

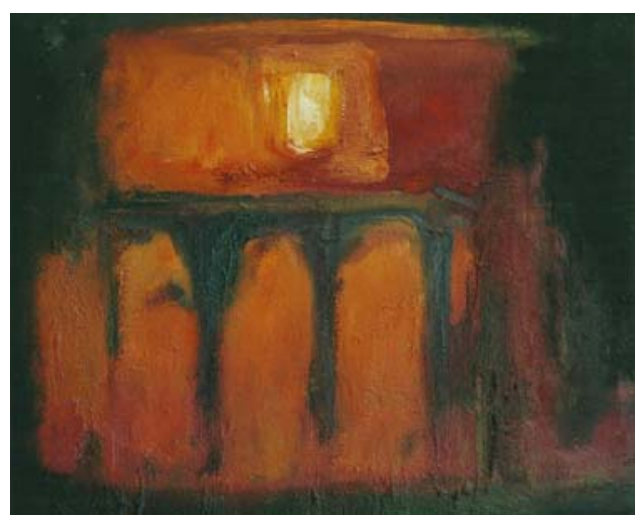

Fig. 12 (sup.) Minu San Martín Homenaje a Friedrich (o/t, 61 x $50 \mathrm{~cm} ., 1998)$.

Fig. 13 (drch) Minu San Martín. Siempre el Cantábrico (o/t, 116 x 89 cm., 1998).

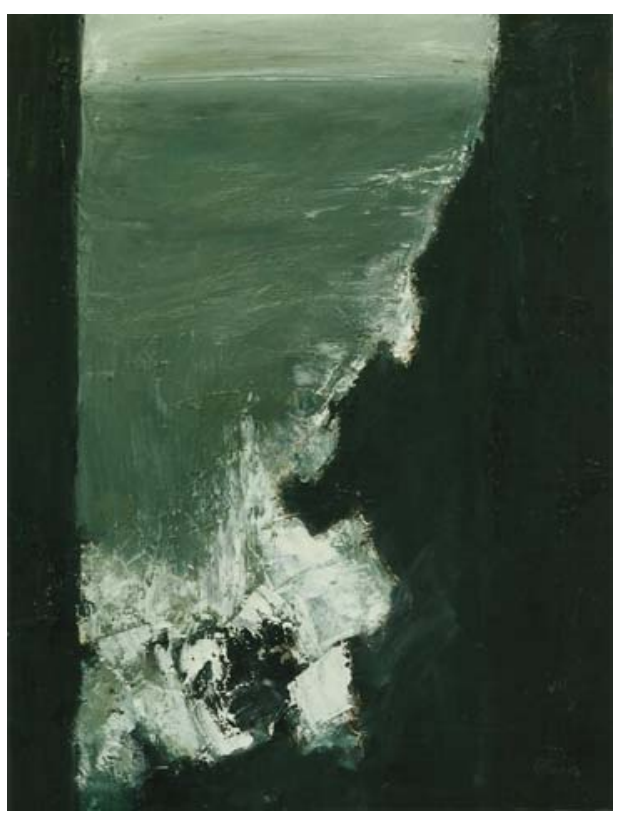

En ese malestar, la artista intuyó que la visión fatalista del hombre romántico podía ser transformada en una visión más amable. Encontró la respuesta en la pintura china de la época Song, donde el paisaje en su estado natural, no rechazaba al hombre, rechazo que sí sentían los románticos, sino 
que, muy al contrario, lo incorporaba. En estas dos visiones surge, una vez más, el eterno conflicto de dualidades del que San Martín está cada vez más concienciada.

Corría el año 2000 y la pintora ya estaba recuperada de su anterior crisis con nuevas ilusiones y proyectos de trabajo. Hizo un viaje por Castilla-La Mancha, que le llevó a recorrer los caminos del Quijote pintando nuevas telas en las que recreaba las vastas extensiones del campo de Ciudad Real y de Toledo. Este viaje daría lugar a la muestra Silencios de Castilla, en Aranda de Duero, donde compartiría la exhibición de sus obras con las poesías de la escritora Cristina Golet, inspiradas en los mismos paisajes. Este tándem artístico se repetirá en otras ocasiones (San Martín Aróstegui y Golet, 2004 y 2013).

Poco después, la pintora trasladaba su taller a La Pobla de Massaluca, un pueblecito de interior, situado en la provincia de Tarragona. Allí vivió unos años de calma y reflexión que dieron como fruto una pintura serena y equilibrada desconocida hasta el momento. Buen ejemplo de ello lo podemos ver en su obra Crepúsculo, (Fig. 14). Tras ese ambiente de calma interior la pintora tomó la decisión de cambiar de escenario, trasladándose a tierras asturianas, concretamente a Gijón. En esa ocasión no se planteó el traslado como un viaje más, ni siquiera como un desplazamiento eventual sino más bien, como un cambio definitivo. Más adelante, el tiempo cambiaría esas circunstancias. El objeto del viaje a Gijón era recuperar la luz del Cantábrico, volver al verde de la tierra, al gris perla del aire y al oscuro profundo de su mar. Recuperar los paisajes de aquellas latitudes iba a ser un soplo de aire fresco, era como recuperar sus orígenes. El ansia con que la artista volvía a afrontar la pintura era buena muestra de este reencuentro emocionado. Siguiendo la tónica de su pintura paisajística, el mar se convertía en el primer protagonista de sus telas. Pero en ese momento aparecía un nuevo elemento en el plano pictórico, que marcaba el inicio de una nueva etapa en la trayectoria de Minu San Martín, se trataba de la figura geométrica.

En obras como Alma Mater, cuadrados y rectángulos de color plano se recortan sobre el paisaje haciendo referencia directa al punto de vista del observador (Fig.15). Aparece aquí un desdoblamiento patente de la artista, que empieza a reconocerse no sólo como artífice de la obra, sino también como observadora de la misma. Algo parecido explicamos en su etapa de 
crisis. En este momento no existe el dramatismo anterior, otorgado por el color y la pincelada violenta, ahora es una pintura más meditada, más controlada, donde la autora parece preguntarse si es posible formar parte de su propio universo.

Fig. 14. Minu San Martín. Crepúsculo $(\mathrm{o} / \mathrm{t}, 30 \times 97 \mathrm{~cm}$., 2013).

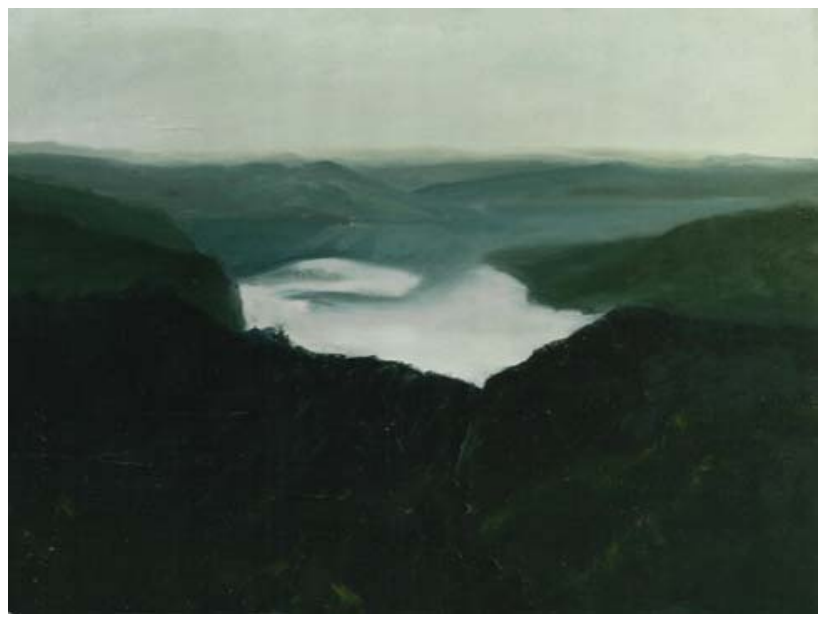

Fig. 15. Minu San Martín. Alma mater. Ola de invierno (Óleo y materia sobre tela, 130 x 89 cm., 2005-2006).

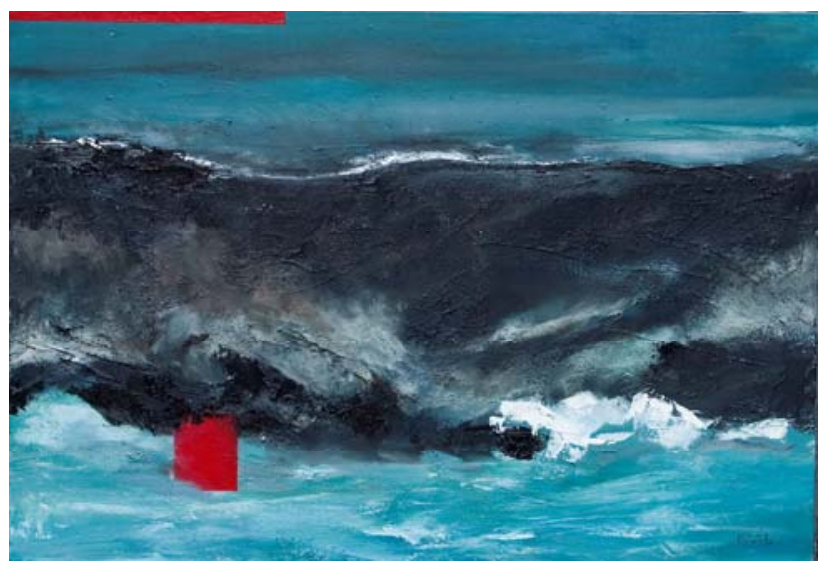

Durante el tiempo que San Martín permaneció en Asturias, realizó varias exposiciones en distintas localidades como Colunga, Gijón y Avilés, en las que el mar, espejo de las emociones humanas (así es como lo define la artista), jugaba un papel preponderante (García, 2006; Díez, 2006; C.C., 2007). Esta renovada ilusión por la vida le llevó asimismo a involucrarse durante un tiempo en la Asociación Unidos por el Arte de Gijón, con la que participó en el montaje de exposiciones colectivas, eventos y en la redacción de textos de presentación de 
sus catálogos. También entabló relación con otros pintores locales como Roberto Valdés Bango y Javier Victorero, gracias a los cuales entró en contacto con las galerías Octógono de Avilés y Costa de Diego de Oviedo, en las que expuso colectiva e individualmente en repetidas ocasiones (San Martín, 2009). Fue precisamente el proyecto de la última exposición que realizó en Asturias, el que le empujó a trabajar sobre el Prerrománico asturiano. San Martín había escrito sobre el Prerrománico vasco-navarro con anterioridad, pues era un estilo arquitectónico que le apasionaba desde que lo estudiara en su juventud (San Martín, 1999) y sobre el que siguió interesada aún bastante tiempo después.

En sus primeros cuadros de la serie Prerrománico (2007-2009), aún no habían desaparecido del todo las geometrías de color plano anteriores, pero en este momento no se muestran recortadas, sino que se funden entre paredes de piedra, ventanas, puertas, capiteles y contrafuertes. Es como si el observador y el pintor hubiesen perdido la distancia con el objeto observado y fueran haciéndose uno. No es de extrañar, pues, que las últimas obras de la serie Prerrománico, que se ejecutan alrededor del año 2010, se distancien absolutamente de las primeras, tanto en técnica como en temática. En éstas, los arcos de medio punto abren el paso al interior de las iglesias y aparece la figura de espaldas, perpleja, dentro de la escena, atraída por la luz interior y por la decoración geométrica de los frescos (Fig. 16). La áspera superposición de capa sobre capa de óleo se dulcifica y afloran unas obras de óleo sobre tabla en las que el tratamiento con la espátula convierte a la misma materia en un aparente temple al huevo bruñido con piedra de ágata, cercano a los antiguos retablos medievales.

Los viajes en autocaravana que San Martín realiza ese mismo año (primero por España y después por Europa), dejan interrumpida esta serie, donde ya queda patente la fusión del pintor-observador y el objeto representado. Al regresar a España, por la frontera de la Jonquera, Barcelona vuelve a ser el destino $y$, de nuevo, su lugar de residencia.

\section{Pintor y observador se hacen uno.}

Una vez más, el traslado de ciudad significaba un nuevo inicio de trabajo, pero ahora las vivencias de varios meses de viaje supondrían realmente un cambio total de planteamientos. En los dos años que permaneció en Barcelona, la búsqueda del motivo ya no estaba en el exterior, sino en el interior de la 
propia artista. Sus diarios de taller, que forman parte habitual de su trabajo, hasta la fecha estaban limitados a reflexiones sobre arte y, más concretamente, sobre el particular desarrollo del proceso pictórico, pero a partir de ahora se van a impregnar de experiencias personales y de pensamientos acerca de la vida. Paralelamente, en la obra el espacio dejaba de estar vacío y aparecía en él un nuevo elemento, el pájaro, como representación simbólica del ser que habita el paisaje, que lo transforma con su presencia, haciéndose partícipe de su entorno. De alguna manera, el observador-pintor se ha hecho presente y quiere ser protagonista de esa vida que antes transcurría fuera de sí mismo.

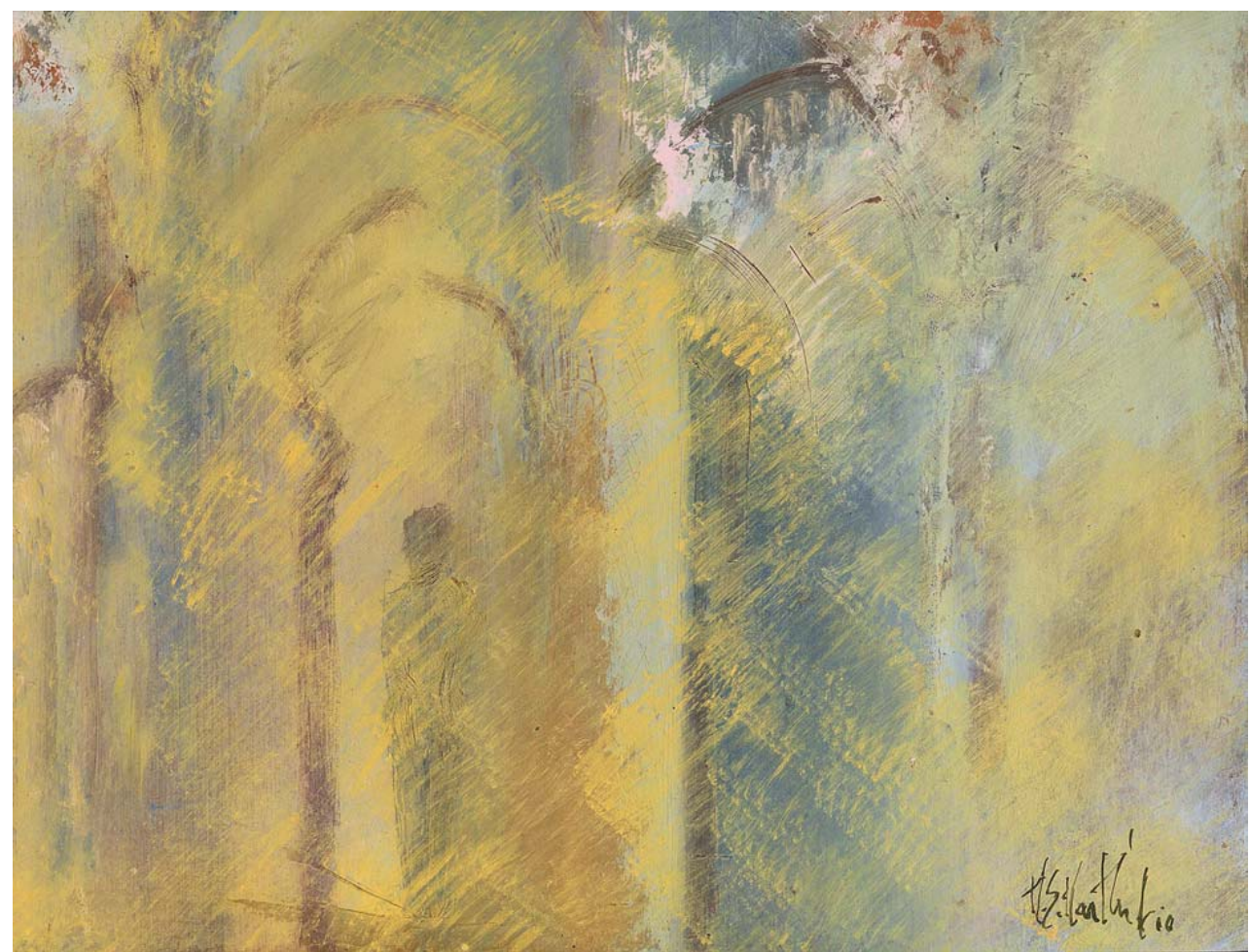

Fig. 16. Incerdidumbre. Óleo sobre tabla, 35 × 26 cm., 2010.

Después de barajar las distintas relaciones que se establecen entre observador y objeto representado, San Martín encuentra el modelo ideal de comportamiento en la visión oriental de la naturaleza, en la que el individuo forma parte de la misma. De esta manera el aterrador abismo romántico da paso al abismo integrador oriental que todo lo contiene. 
En diciembre de 2012 Minu San Martín, cansada del bullicio de la gran ciudad, abandonó Barcelona y, buscando la cálida luz del Sur, se trasladó a vivir a la Costa del Sol malagueña. La primera exposición a la que concurrió, en el mes de abril de 2013, fue la colectiva que se celebró en la Sala Imaz de San Sebastián, titulada Factor humano. 4 miradas (Arrieta, 2013). La exhibición, cuyo motivo unificado era la figura humana, fue compartida con Ana María Parra, Sofía Aróstegui y Patxi Aróstegui. Ahora las obras de Minu San Martín cambiaban a colores más vivos y atrevidos, presentando así un punto de inflexión en su andadura. El trabajo de esta muestra estaba basado en las reflexiones aprendidas gracias a la observación del trabajo espiritual de Cristina Golet, modelo a su vez de todas las figuras del conjunto, al que la pintora dio por título: El ser que medita. Para entender lo que la pintora quiso expresar, extraemos un fragmento de su diario:

[...] Busco al ser que adquiera todo el sentido por sí mismo. Que tenga miles de significados, tantos como descubrimientos vitales. Busco al que da, al que recibe, al que se desdobla, al que se multiplica, al que es reflejo, al que es cofre, al que es luz, al que es transparente, al que es inmóvil, al que está en varios tiempos en el mismo espacio, al que se desplaza en el espacio en el mismo tiempo, al que genera silencio, al que se confunde con su entorno, al respetado, al temido...y aparece la figura de la yogui. No hace desplantes, no mira al futuro, no se acuerda del pasado y vive el presente. El espacio que ocupa se convierte en luz y esa luz la atraviesa. Sale de ella y vuelve a ella. Es una figura femenina que genera su propio entorno, esté donde esté. Aúna pensamientos y creencias en una sola emoción y en una sola fe. Respira paz, transmite paz. Forma parte del aire y lo engrandece con su presencia. Está en ella misma. Mira de frente. Nada importa lo que hay a su espalda. Y cuando medita, las fuerzas de la naturaleza se humanizan. La tormenta se asusta de la calma que encuentra a su paso. El mar se paraliza. El árbol vuelve a tierra a enraizar después de haber crecido. La yogui atrae a los elementos; se convierte en los elementos; es respetada por los elementos; y el verde arropa su silencio ${ }^{10}$.

Tras unos meses en Málaga y gracias a la amistad con el pintor Pedro Escalona, el Ayuntamiento de Alhaurín el Grande propuso a Minu San Martín una exposición en la Sala de la Biblioteca Municipal de la localidad ${ }^{11}$. Esta

\footnotetext{
${ }^{10}$ San Martín Aróstegui, M., (2013), Diario de Taller, 15 de abril, Alhaurín el Grande.

${ }^{11}$ Ayuntamiento de Alhaurín el Grande, "La pintora Minu San Martín expone Paisajes de mi memoria en Alhaurín el Grande". En: http://www.alhaurinelgrande.net/alhauPortal/ contene-
} 
exposición, que se tituló Paisajes de mi memoria, acogió más de 70 piezas de diferentes momentos de la trayectoria artística de la artista, pero no por ello se entendió como una retrospectiva o un recopilatorio. La disposición de las obras hizo más bien referencia a su proceso de trabajo. Se mostraron grandes telas junto a escritos, paneles de series sobre papel de pequeño formato y vitrinas con un buen número de cuadernos (de viaje, apuntes del natural, de bocetos, desarrollo de ideas), que hasta este momento nunca habían salido del estudio.

Fruto de su estancia en tierras andaluzas, aparecieron en su imaginario personal el toro y el torero, elementos que incorporó también a esta exposición y con los que aún hoy sigue trabajando. No son las típicas estampas del mundo taurino que tanto hemos visto proliferar en el mercado artístico. En esta serie, la artista continúa su tendencia colorista, adentrándose en los motivos para transformarlos en símbolos que sirvan a su discurso interno. Una vez más aflora la dualidad y torero y toro se convierten en la razón y en la naturaleza incontrolada, las dos caras del individuo en conflicto consigo mismo. Cuando el toro desaparece, el torero adquiere ante el paisaje un protagonismo sereno que le convierte en una metáfora de la actitud de la propia artista ante la vida, una vida en pleno crecimiento que Minu San Martín afronta con la madurez que corresponde a su amplia trayectoria vital y artística, y que hoy por hoy, es el motivo que mantiene alerta a la pintora y da contenido a su trabajo.

\section{Bibliografía.}

BENEJAM, (1989): “El arte moderno: Crisis o renovación”, Ultima Hora, Menorca, 27 de septiembre de 1989.

C. C., (2007): "Pinto sobre realidades vividas", El Comercio, Gijón, 27 de agosto de 2007.

dor1.jsp?seccion=s_fnot_d4_v1.jsp\&contenido=7385\&tipo=8\&nivel=1400\&codResi=1\&language =es ;(05/07/2013). Recuperado el 30/08/2013; Arrieta, A., “Exposición de Minu San Martín en Alhaurín el Grande Paisajes de mi memoria". En: http://www.youtube.com/watch?v=xMHctUuHqs, (01/08/2013). Recuperado el 30 de agosto de 2013; Estrella, “La pintora Minu San Martín expone "Paisajes de mi memoria" en Alhaurín el Grande". En: http://www.elaguijon.es/ content/la-pintora-minu-san-mart $\%$ C3\%ADn-expone- $\%$ E2\%80\%9Cpaisajes-de-mi-memoria $\%$ E2 $\%$ 80\%9D-en-alhaur\%C3\%ADn-el-grande. (05/07/2013). Recuperado el 30/08/2013. 
CARNÉ, M. y SAN MARTíN, M., (1989): “Una conversa sobre Arco 89”, Quadern, no 66, Sabadell, febrero 1989, p. 333.

CARNÉ, M. y SAN MARTÍN, M., (1992): Emili Bonet, Ámbit, Barcelona.

DE LA VILLA, R., (1998): Guía del usuario de arte actual, Madrid, Tecnos.

DíEZ, Z., (2006): “Mi obra se basa en el Cantábrico", La Voz de Avilés, 5 de octubre de 2006.

GarcíA, B. M., (2006): “Minu San Martín lleva a la casa de Cultura 18 paisajes abstractos", El Comercio, Colunga, 18 de junio de 2006.

J. B., (1995): “Fets de silenci", La Vanguardia, 15 de diciembre de 1995, p. 48.

J. D. E., (1991): “El paisaje mediterráneo visto por una donostiarra, en Estudio de San Sebastián", Egin, San Sebastián, 4 de diciembre de 1991.

JuAN, J., (2001): “Minu San Martín”, Arde Barcelona, nº 11, Barcelona, enero 2001, p. 27.

MElis PONS, P., (1993): “Sensacions, paraules, imatges...", Diario Insular, 25 de abril de 1993.

Petrus, Isabel, (1993): “El sexo de los ángeles", Diario Insular, 3 de abril de 1993.

SAN MARTín ARÓSTEGUI, M., “Darreries segle XX”, en SANTOS TORROELlA, R. (dir.), Enciclopèdia Vivent de la pintura i l'escultura catalanes, Àmbit, Barcelona, 1991, vol. XIII y XIV.

SAN MARTíN ARÓSTEGUI, M., (1989a): “Dalí, un actor surrealista”, Quadern, no 66, Sabadell, febrero, 1989.

_ (1989b): “1ํㅜ Triennal del gravat de Sabadell”, Quadern, no 68, Sabadell, 1989, p. 442.

_ (1990a): "El paisatge: ahir i avui", Quadern, no 70, Sabadell.

_ (1990b): “Las Meninas. Una significació amagada”, Quadern, no 71, Sabadell.

_ (1994): Exposición Ciudad Escondida, Galería Olaetxea, celebrada del 4 de noviembre al 5 de diciembre, Galería Olaetxea, San Sebastián.

_ (1995a): "Ciudad de silencio", MAGMA Gaseta d'Arts, no 0, Barcelona.

_ (1995b): Paisaje. Tiempo de recorridos, Exposición en Galería Hemen, celebrada del 3 de noviembre al 28 de noviembre, Guetaria. 
_ (1997): El instante y la eternidad. Un tiempo de la pintura. Dirigida por Gerard Sala. Tesis doctoral inédita. Universidad de Barcelona, Departamento de Pintura.

_ (1999): "El Prerrománico Vasco-Navarro" y "El Románico Vasco-Navarro", LEVY, André, (dir.): Le dictionaire des Pyrénées. Encyclopédie illustrée FranceEspagne, Privat, Toulouse.

- (2009): Exposición Minu San Martín A., Exposición en Galería Costa de Diego, celebrada del 16 de junio al 3 de julio, Oviedo.

SAN MARTín Aróstegui, M., y Golet, C., (2004): Silencios de Castilla, Exposición celebrada en Casa de Cultura, inaugurada 18 junio, Aranda de Duero.

_ (2013): Exposición Paisajes de mi memoria, Muestra en Sala Exposiciones Biblioteca Alhaurín el Grande, celebrada del 4 de Julio al 31 de agosto, Alhaurín el Grande.

STERLING, Ch., (1959): "La Peinture de paysage en Europe et en Chine", en Orient-occident: rencontres et influences durant cinquante siècles d'art: novembre 1958-février 1959, Musées Nationaux, París, p.14.

VIDAL, J., (1996): “Portes que s'obren i es tanquen”, El País, 5 de febrero de 1996, p. 10.

V.J., (1997): “Triangle, Associació d'Art Contemporani", El País, 8 de mayo de 1997.

\section{Recursos electrónicos.}

ARRIETA, A., (02/05/2013). Exposición de pintura y fotografía, "Factor humano, cuatro miradas". Recuperado el 30 de agosto de 2013 desde http://youtu.be/VDXua4NuDi0.

_ (01/08/2013). “Exposición de Minu San Martín en Alhaurín el Grande Paisajes de mi memoria". En: http://www.youtube.com/watch?v=xMHctUu-Hqs. Recuperado el 30 de agosto de 2013.

Ayuntamiento De Alhaurín El GRAnde, (05/07/2013). “La pintora Minu San Martín expone Paisajes de mi memoria en Alhaurín el Grande". En: http://www.alhaurinelgrande.net/alhauPortal/contenedor1.jsp?seccion=s_f 
not_d4_v1.jsp\&contenido=7385\&tipo=8\&nivel=1400\&codResi $=1 \&$ language =es. Recuperado el 30/08/2013.

EstrellA, (05/07/2013). “La pintora Minu San Martín expone "Paisajes de mi memoria" en Alhaurín el Grande". En: http://www.elaguijon.es/content/lapintora-minu-san-mart $\%$ C3\%ADn-expone-\%E2\%80\%9Cpaisajes-de-mi-me moria\%E2\%80\%9D-en-alhaur\%C3\%ADn-el-grande recuperado 30/08/2013

Ruíz De AzÚA, V., (28/11/1980). “Asesinado el Jefe de la Policía Municipal de San Sebastián”. En: http://elpais.com/diario/1980/11/28/espana/344214001 _850215.html, El País, San Sebastián, recuperado el 15/12/2013. 